\title{
USO DE GEOTECNOLOGIAS PARA AVALIAÇÃO DE MUDANÇAS NA COBERTURA VEGETAL DO ENTORNO DA ILHA DA LUZ
}

\author{
Caroline Tavares Firmino' \\ Gizely Azevedo Costa ${ }^{2}$ \\ Lucyelen Costa Amorim ${ }^{3}$ \\ Mayara Cazadini Carlos ${ }^{4}$ \\ Jefferson Luiz Ferrari ${ }^{5}$
}

Resumo: Os impactos decorrentes da ação antrópica podem ser vistos no solo, nas águas, na flora e na fauna. Como meio de monitorar esses impactos tem sido utilizada técnicas por meio do geoprocessamento, as quais são de suma importância, por fornecerem a possibilidade de monitorar as questões ambientais através de imagens obtidas via sensores orbitais. Objetivou-se analisar as mudanças ocorridas na formação vegetacional do entorno da llha da Luz em Cachoeiro de Itapemirim a partir da apreciação de duas imagens do Google Earth. Para a realização da análise temporal as imagens orbitais selecionadas foram importadas do Google Earth para o Autocad, onde foram realizadas as demarcações e medições das formações vegetacionais do entorno da llha. Constatou-se um aumento de $1127.0002 \mathrm{~m}^{2}$ da área vegetacional da Ilha da Luz entre as duas imagens, decorrente da agregação de fragmentos, demonstrando que as ferramentas computacionais são relevantes para avaliação de impactos ambientais.

Palavras-chave: Análise temporal; Cobertura vegetal; Geotecnologias.

\footnotetext{
${ }^{1}$ Bacharelado em Ciências Biológicas/Instituto Federal do Espírito Santo - Campus de Alegre, Alegre, ES, Brasil. E-mail: tavares.carolini@gmail.com.

2 Bacharelado em Ciências Biológicas/Instituto Federal do Espírito Santo - Campus de Alegre, Alegre, ES, Brasil. E-mail: gizelyac.11@hotmail.com.

${ }^{3}$ Bacharelado em Ciências Biológicas/Instituto Federal do Espírito Santo - Campus de Alegre, Alegre, ES, Brasil. E-mail: lucyelen_amorim@hotmail.com.br.

${ }^{4}$ Bacharelado em Ciências Biológicas/Instituto Federal do Espírito Santo - Campus de Alegre, Alegre, ES, Brasil. E-mail: may_cazadini@hotmail.com.

5 Professor Doutor/Instituto Federal do Espírito Santo - Campus de Ibatiba, Ibatiba, ES, Brasil. E-mail: ferrarijluiz@gmail.com.
} 